\title{
Características y costos directos de infecciones respiratorias agudas en niños de guarderías infantiles
}

\author{
Luis Delpiano M., Paola Kabalán B., Constanza Díaz V. y Andrea Pinto I.
}

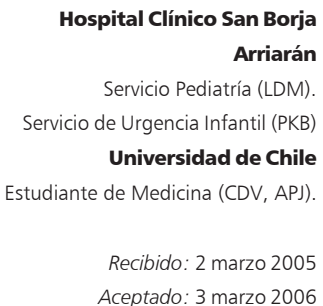

Correspondencia a: Luis Delpiano Méndez ludelpia@vtr.net

\section{Acute respiratory infections in children of day care center: Characteristics and costs}

The clinical profile of respiratory infections in 140 children who attend a day care center was described in a prospective study and direct costs were estimated. The costs estimation included diagnostic procedures, laboratory exams, drugs, kinesitherapy, parents' absenteeism, medical certificates and hospitalization. Two hundred and two respiratory episodes in $90(64.2 \%)$ children, $75(37.1 \%)$ in 30 infants and $127(62.8 \%)$ in 60 toddlers were analyzed. There were $61.3 \%$ lower respiratory infections in infants versus $39.4 \%$ in toddlers $(\mathrm{p}<0.002)$. Antimicrobials were prescribed in $42.6 \%$ of the medical attendance. Infants represent major costs regarding medical consultations, kinesitherapy, laboratory tests and refunds for medical certificates or leave of absence $(p<0.001)$. The mean global cost of a respiratory infection was US $\$ 129,3$ for infants and US $\$ 53,0$ for toddlers $(p<0.001)$. This situation needs the development of an intervention program.

Key words: day care center, respiratory infections, diseases costs.

Palabras claves: guardería infantil, infecciones respiratorias, costos de enfermedad.

\section{Introducción}

$\mathrm{L}$ a asistencia de menores a guarderías infantiles, debido a sus características fisiológicas y necesidades especiales de atención, involucra un mayor riesgo de adquirir patologías infecciosas, principalmente de los tractos respiratorio y digestivo. Estos niños son además, un grupo selecto con elevado consumo de antimicrobianos y que, secundariamente a la patología infecciosa, provoca impacto económico y social ${ }^{1,2}$. En la génesis de estas infecciones intervienen factores del hospedero (edad, hábitos higiénicos, grado de maduración inmunológica), del ambiente (espacio físico, contaminación con secreciones y excreciones) y características del patógeno, y sin olvidar en esta edad, la frecuente existencia de infección asintomática o el estado de portación ${ }^{3}$.

Las infecciones respiratorias se presentan principalmente en lactantes, con una frecuencia dos a tres veces mayor que en niños que no asisten a guarderías infantiles. La mayoría son autolimitadas y de etiología viral, con transmisión por gota grande aunque también puede existir transmisión por gota pequeña (varicela). En caso de brotes las tasas de ataque pueden elevarse hasta $100 \%$ en los expuestos susceptibles ${ }^{4,5}$. Los virus respiratorios presentes en las guarderías infantiles son reflejo, generalmente, de su epidemiología en la comunidad, existiendo infecciones por virus respiratorio sincicial (VRS), virus parainfluenza, virus influenza, adenovirus y bacterias como Streptococcus pneumoniae, Haemophilus influenzae tipo b, Neisseria meningitidis y Streptococcus. pyogenes. Su transmisión es por inoculación directa de partículas infecciosas desde otros niños o desde adultos enfermos, sin olvidar por ejemplo el riesgo de transmisión de Bordetella pertussis desde adultos asintomáticos a lactantes no vacunados ${ }^{6,7}$. En este grupo etario existen elevadas tasas de portación de bacterias potencialmente patógenas; una publicación nacional ${ }^{8}$ comprobó la portación de $S$. pneumoniae en niños asistentes a guarderías infantiles en Santiago, entre 3 meses y 4 años de edad, con una frecuencia de $60,2 \%$ y resistencia a penicilina en $28,4 \%$ de las cepas aisladas.

Nafstad evaluó la salud respiratoria, a través de un cuestionario, en niños asistentes a guarderías infantiles en Oslo incluyendo a 3.853 niños de 3 a 5 años, y encontró mayor tos nocturna y obstrucción nasal que en los niños controles, mayor riesgo de resfrío común $(17,4 \%)$, otitis media aguda-OMA $(32,4 \%)$ y mayor diagnóstico de asma bronquial en lactantes9. Así mismo, la asistencia de lactantes a guarderías infantiles se reporta como factor de riesgo para enfermedad grave por VRS ${ }^{10}$.

En lo relativo a costos, un estudio canadiense ${ }^{11}$ 
consideró costos directos e indirectos en niños de guarderías infantiles respecto de patologías como resfrío, diarrea y vómito; el seguimiento de 273 niños durante 6 meses permitió estimar un gasto promedio de \$ 260,70 dólares canadienses por episodio. En Chile, no existe conocimiento de costos directos en este tipo de morbilidad en esta población, de allí que su estimación resulte importante para evaluar su impacto e implementar medidas de prevención y control de infecciones en guarderías infantiles.

Los objetivos de este trabajo son:

- describir el perfil clínico de las infecciones respiratorias agudas en época invernal, en niños asistentes a una guardería infantil dependiente de un hospital público en Santiago.

- medir costos directos de estas infecciones, evaluando diferencias al comparar valores entre lactantes y pre-escolares.

\section{Pacientes y Método}

Con un diseño de estudio descriptivo transversal, y luego de obtener autorización de la dirección del establecimiento, educadoras de párvulos y padres o tutores de los menores, se efectuó un seguimiento de niños asistentes a la guardería infantil para hijos de funcionarios del Hospital Clínico San Borja Arriarán (HCSBA). Se creó una base de datos con los números telefónicos del lugar de trabajo y domiciliario de padres o tutores para facilitar el contacto y seguimiento de los menores.

La población a vigilar correspondió a 140 niños: 49 lactantes del nivel sala cuna con un promedio de edad de 17 meses y 91 pre-escolares que asistían al nivel jardín infantil, con un promedio de edad de 3,5 años, desde mayo a agosto del año 2004. Se efectuó visita trisemanal con las educadoras de párvulos a fin de obtener datos de inasistencia. Frente a cada inasistencia confirmada por enfermedad respiratoria que hubiese requerido de asistencia médica (decisión de consulta tomada por los padres), se realizó una entrevista al apoderado, primero telefónica y luego personal cercana al evento mórbido, aplicando un cuestionario sobre los siguientes tópicos: morbilidad, variables generales (edad, sexo, salario mensual, sistema previsional de salud) morbilidad respiratoria: diagnóstico entregado por el médico, exámenes efectuados, terapia indicada (medicamentos), consultas médicas (hospitalarias y extra-sistema), ausentismo laboral (permiso) y/o licencia médica y hospitalización, gasto económico en pesos cuando correspondiese.

Los diagnósticos médicos entregados a los apoderados en las respectivas consultas fueron clasificados como infecciones respiratorias (IRA) altas o supralaríngeas: refrío común, faringitis, herpangina, amigdalitis, laringitis, OMA; o infecciones respiratorias $b a$ jas: bronquitis obstructiva y neumonía. Se consideró dos niveles de costos o gastos: en primer lugar, el promedio del costo asumido por los apoderados, y en segundo lugar, el costo total por evento respiratorio considerando valor de bonos de atención o de exámenes y subsidios del tipo licencia médica por hijo bajo 1 año de edad o permiso laboral.

Para valores de costo de exámenes se consideró el pagado por los apoderados y el valor de la orden de atención de acuerdo al sistema de previsión de salud o arancel FONASA en cada caso (FONASA: Fondo Nacional de Salud, sistema de seguro estatal de salud). Para valor consulta se asumió valor cancelado y valor co-pago FONASA o ISAPRE (ISAPRE: Institución de Salud Provisional, sistema de seguro privado obligatorio de salud). Para valores de medicamentos se consideró el cancelado por los padres o el valor comercial vigente en farmacia de cadena o el arancel de fármacos hospitalarios. Para terapias de apoyo, como kinesiología, se consideró el valor cancelado por los apoderados y el costo ISAPRE o FONASA. Se contabilizó el total de días no trabajados (licencias o permisos), y el cálculo de valor de ausentismo laboral se efectuó de acuerdo al valor día según remuneración hospitalaria (salario dividido en 30 días). Cada costo sumado fue traducido a promedio en pesos. La mayoría de la información se presenta diferenciada para lactantes asistentes a sala cuna y pre-escolares asistentes a jardín infantil*.

Análisis estadístico. Los datos se trabajaron en planilla excel y se realizó cálculos de promedios, mediana, desviación estándar, mínimos y máximos de los costos estudiados. Se efectuó pruebas de significación estadística, exigiendo nivel de significación $\pm=$ 0,05 para grupos de datos con proporciones independientes o con desviaciones estándar. El análisis estadístico se efectuó en programa acastat 5.0.

\section{Resultados}

Durante los 4 meses de vigilancia se reportó y evaluó 202 eventos mórbidos respiratorios en 90 (64,2\%) de los 140 niños inscritos en la guardería infantil: 75 en 30 de sala cuna y 127 en 60 de jardín infantil. Respecto de otros antecedentes de los niños con morbilidad respiratoria, 28 lactantes y 53 pre-escolares pertenecían a FONASA, el resto de los menores se encontraba afiliado a algún sistema de ISAPRE.

* Para la conversión en dólares americanos se consideró US 1 = 530 pesos chilenos. 
El salario líquido promedio del funcionario apoderado del menor enrolado perteneciente a sala cuna o jardín infantil fue de $\$ 186.625$ (aproximadamente 350 dólares americanos) y $\$ 207.500$ ( US 390) respectivamente. El promedio de hijos por familia fue de 2,37 y 1,98 para niños de sala cuna y jardín infantil (Tabla 1).

Diagnósticos médicos. Es destacable la presentación de $29(38,7 \%)$ infecciones respiratorias altas en lactantes versus $77(60,6 \%)$ en pre-escolares $(\mathrm{p}<0,003)$ y $46(61,3 \%)$ infecciones respiratorias bajas en lactantes

\begin{tabular}{|c|c|c|c|c|c|}
\hline & Lact & $\begin{array}{l}\text { tantes } \\
\text { n }\end{array}$ & Pre-e & $\begin{array}{l}\text { scolare } \\
\text { n }\end{array}$ & \\
\hline Inscritos & 49 & & 91 & & \\
\hline Edad promedio (meses) & 17 & & 42 & & \\
\hline Enfermaron & 30 & & 60 & & \\
\hline$N^{\circ}$ hermanos promedio & 2,37 & & 1,98 & & \\
\hline$N^{\circ}$ eventos mórbidos $(n=202)$ & 75 & & 127 & & \\
\hline Varones enfermos (\%) & 17 & $(56,7)$ & 24 & $(40,0)$ & \\
\hline Beneficiarios FONASA (\%) & 28 & $(93, \%)$ & 53 & $(88,3)$ & \\
\hline Sueldo promedio (\$) & 186.625 & $(\sim$ US: 350$)$ & 207.500 & $(\sim$ US & 390) \\
\hline IRA alta (\%) & 29 & $(38,7)$ & 77 & $(60,6)$ & * \\
\hline IRA baja (\%) & 46 & $(61,3)$ & 50 & $(39,4)$ & $* *$ \\
\hline \multicolumn{6}{|c|}{$\begin{array}{l}\text { IRA }=\text { infección respiratoria aguda } \\
{ }^{*} p<0,003 \quad{ }^{* *} p<0,002 \\
\text { FONASA: Fondo Nacional de Salud (ver texto) } \\
\text { Un dólar americano }=530 \text { pesos chilenos }\end{array}$} \\
\hline
\end{tabular}

Tabla 2. Indicación de antimicrobianos según diagnóstico en infecciones respiratorias en niños de sala cuna y jardín infantil. Santiago, mayo - agosto 2004

\begin{tabular}{lrrrrrrr} 
Diagnóstico & \multicolumn{3}{c}{ Sala Cuna } & \multicolumn{3}{c}{ Jardín infantil } \\
& $\mathbf{n}$ & $\mathbf{c / A M}$ & $\mathbf{( \% )}$ & $\mathbf{n}$ & $\mathbf{c} / \mathbf{A M}$ & $\mathbf{( \% )}$ \\
Resfrío común & 14 & 1 & $(7,1)$ & 18 & 5 & $(27,8)$ \\
Faringitis & 10 & 3 & $(30,0)$ & 29 & 9 & $(31,0)$ \\
Otitis media & 3 & 3 & $(100)$ & 5 & 5 & $(100)$ \\
Herpangina & 2 & 1 & $(50,0)$ & 15 & 15 & $(100)$ \\
Amigdalitis & 0 & - & - & 5 & 3 & $(60,0)$ \\
Laringitis & 0 & - & - & 5 & 1 & $(20,0)$ \\
Bronquitis obstructiva & 39 & 14 & $(35,9)$ & 42 & 15 & $(35,7)$ \\
Neumonía & 7 & 6 & $(85,7)$ & 8 & 5 & $(62,5)$ \\
\hline Total & 75 & 28 & $(37,3)$ & 127 & 58 & $(45,7)$ \\
\hline * AM: antimicrobiano & & & & & & \\
\hline
\end{tabular}

versus $50(39,4 \%)$ en pre-escolares $(\mathrm{p}<0,002)$ (Tabla 1$)$. Entre las IRAs altas de pre-escolares predominó el diagnóstico de faringitis, herpangina y resfrío común (49\% del total), y entre las IRAs bajas de lactantes el síndrome bronquial obstructivo $(61,3 \%$ del total). Se diagnosticó 15 neumonías, 7 en lactantes. Se solicitó identificación etiológica sólo en 1 lactante con SBO, demostrándose VRS por inmunofluorescencia.

Hubo 61 (30,2\%) eventos resueltos luego de efectuar consulta al médico a cargo de la guardería infantil, recurriendo en el resto de los episodios a Servicios de Emergencia en $52(25,7 \%)$ ocasiones y médicos de consulta privada en $89(44,1 \%)$ eventos. Durante el período de estudio, 3 lactantes fueron internados en el Servicio de Pediatría del HCSBA con diagnósticos de: bronquitis obstructiva y neumonía de focos múltiples.

Se indicó antimicrobianos en $86(42,6 \%)$ de los 202 episodios respiratorios, $28(37,3 \%)$ en lactantes y 58 $(45,7 \%)$ en pre-escolares. Recibieron terapia con antimicrobianos la totalidad de los pacientes con OMA, $73,3 \%$ de los con neumonía, 28\% de los con resfrío común y $100 \%$ de los pre-escolares con herpangina (Tabla 2). Los antimicrobianos indicados fueron principalmente $\beta$ lactámicos (amoxicilina, amoxicilina/ácido clavulánico, cefadroxilo) y macrólidos (eritromicina, claritromicina y azitromicina). En sala cuna, 27,5\% de los pacientes con IRAs altas y 43,4\% de las IRAs bajas recibió tratamiento antimicrobiano, versus 49,3 y 40\% en niños asistentes a jardín infantil, respectivamente.

Costos directos. Evaluados separadamente para lactantes y pre-escolares, el valor total de las consultas médicas efectuadas por niños de sala cuna fue de $\$ 911.360$ ( US1.720) (promedio \$ 12.151) ( US 23) y para niños de jardín infantil \$ 1.084 .490 ( US 2.046) (promedio \$8.539, ( US 16) con $\mathrm{p}<0,003$ (Tablas 3 y 4). El valor de los exámenes de laboratorio efectuados y los procedimientos kinésicos alcanzaron un costo total de \$ 506.190 ( US 955) y 235.210 ( US 444) para los primeros y $\$ 266.670$ ( US 503) y 29.390 ( US 55) para los segundos, en lactantes y pre-escolares respectivamente.

El valor total alcanzado por gasto en fármacos (antipiréticos, antitusivos, mucolíticos, antimicrobianos, descongestionantes e inhaladores) fue de $\$ 998.080$ $(\sim$ US 1.883) para la morbilidad en lactantes y $\$ 1.534 .935$ $(\sim$ US 2.896) en niños de jardín infantil, con promedios de \$ $13.672(\sim \operatorname{US} 26)$ y $\$ 21.618(\sim \operatorname{US} 41)(\mathrm{p}<0,31)$.

Las hospitalizaciones de 3 lactantes tuvieron costo de $\$ 235.000$ ( US 443).

Costos indirectos. En el ámbito del costo representado por licencias médicas (principalmente por hijo bajo 12 meses de edad), permisos (días administrativos) o vacaciones solicitadas motivadas por los episodios de morbilidad respiratoria de los menores, hubo 

Santiago, mayo - agosto 2004

\begin{tabular}{|c|c|c|c|c|c|c|c|c|}
\hline \multirow[t]{2}{*}{ Item } & \multicolumn{2}{|c|}{ Costo prestador de salud } & \multicolumn{2}{|c|}{ Costo paterno } & \multicolumn{2}{|c|}{ Total } & \multirow{2}{*}{$\begin{array}{ll}\text { Promedio por } \\
\text { (\$) US }\end{array}$} & \multirow{2}{*}{$\begin{array}{l}\text { evento } \\
\text { (aprox) }\end{array}$} \\
\hline & (\$) & US* (aprox) & (\$) & US (aprox) & (\$) & US (aprox) & & \\
\hline Consultas & 517.390 & 972 & 393.970 & 743 & 911.360 & 1.719 & 12.151 & 23 \\
\hline$(n=34)$ & 465.050 & 877 & 41.140 & 77 & 506.190 & 955 & 14.888 & 28 \\
\hline$(n=73)$ & 223.665 & 422 & 774.415 & 1.461 & 998.080 & 1.883 & 13.672 & 26 \\
\hline Kinesioterapia $\quad(n=18)$ & 86.320 & 155 & 148.890 & 281 & 235.210 & 444 & 13.067 & 25 \\
\hline Licencias/permisos $(n=40)$ & 2.226 .454 & 4.200 & ------- & & 2.226 .454 & 4.200 & 55.661 & 105 \\
\hline Hospitalización & 235.000 & 443 & ------- & & 235.000 & 444 & 78.333 & 148 \\
\hline Otros & -------- & & 31.000 & 58 & 31.000 & 59 & --------- & \\
\hline Total & 3.753 .879 & 7.082 & 1.389 .415 & 2.621 & 5.143 .294 & 9.704 & 68.577 & 129 \\
\hline
\end{tabular}

\begin{tabular}{|c|c|c|c|c|c|c|c|c|}
\hline \multirow[t]{2}{*}{ Item } & \multicolumn{2}{|c|}{ Costo prestador de salud } & \multicolumn{2}{|c|}{ Costo paterno } & \multicolumn{2}{|c|}{ Total } & \multirow{2}{*}{$\begin{array}{l}\text { Promedio } \\
\text { (\$) }\end{array}$} & \multirow{2}{*}{$\begin{array}{l}\text { por evento } \\
\text { US (aprox) }\end{array}$} \\
\hline & (\$) & US* (aprox) & (\$) & US (aprox) & (\$) & US (aprox) & & \\
\hline Consultas & 731.990 & 1.381 & 352.500 & 665 & 1.084 .490 & 348 & 8.539 & 16 \\
\hline Exámenes & 212.670 & 401 & 54.000 & 101 & 266.670 & 503 & 10.667 & 20 \\
\hline$(n=71)$ & 381.665 & 720 & 1.153 .270 & 2.175 & 1.534 .935 & 2.897 & 21.619 & 41 \\
\hline Kinesioterapia & 29.390 & 55 & ------ & & 29.390 & 55 & 7.347 & 14 \\
\hline Permisos /ausentismo $(n=31)$ & 624.027 & 1.177 & --------- & & 624.027 & 1.177 & 20.130 & 38 \\
\hline Otros & -------- & & 33.000 & 62 & 33.000 & 62 & ------- & \\
\hline Total & 1.979 .742 & 3.735 & 1.592 .770 & 3.005 & 3.572 .512 & 6.740 & 28.130 & 53 \\
\hline
\end{tabular}

un total de 456 días laborales no trabajados. Traducidos en dinero, representan en el nivel lactantes un costo económico total de $\$ 2.226 .454(\sim$ US 4.200) y en pre-escolares de $\$ 624.027$ ( US 1.177) $(\mathrm{p}<0,0001)$.

Finalmente existió un rubro denominado como extras, originado en pago a terceros por el cuidado de los menores en el domicilio: \$31.000 ( US 58,5) en lactantes y $\$ 33.000$ ( $\sim$ US 62) en pre-escolares.

Costos globales. Infecciones respiratorias altas: específicamente, el costo total promedio para resfrío común fue de \$ 31.572 ( US 60) en lactantes y \$ 15.334 ( US 29) en pre escolares; y para faringitis fue de $\$ 26.542$ ( US 50) y \$ 20.354 ( US 38) para lactantes y pre-escolares respectivamente.

Infecciones respiratorias bajas: la sumatoria de bronquitis obstructiva y neumonías alcanzó como valor total \$ $82.436(\sim$ US 155$)$ en lactantes y $\$ 42.165(\sim$ US $79,5)$ en pre-escolares.

Con todo y considerando la sumatoria de todos los costos directos registrados, se promedia y define por episodio de infección respiratoria un valor de \$ 68.577 ( US 129) en lactantes y \$ 28.130 ( US 53) en preescolares de jardín infantil.

Si se excluye el gasto originado por ausentismo laboral (licencias médicas, vacaciones, permisos), el ítem denominado "otros" y el cancelado por los padres, se obtiene el promedio de costo directo a cargo del prestador de salud que alcanza a \$ 20.366 ( US 38) por evento respiratorio de lactante de sala cuna y $\$ 10.675$ ( US 20) para pre-escolares de jardín infantil.

Finalmente, al retirar todos los subsidios económi- 
cos obtenidos como beneficiarios de FONASA o ISAPRE y cuantificar exclusivamente los desembolsos efectivos en dinero en que incurrieron los padres por evento infeccioso respiratorio, se obtiene un costo directo promedio en lactantes de $\$ 18.525$ ( US 35) y de $\$ 12.541$ ( US 24) en niños de jardín infantil.

\section{Discusión}

Este estudio, entrega por primera vez información nacional respecto de algunas características y costos de infecciones respiratorias en un grupo de niños de 6 meses a 5,5 años que asisten a una guardería infantil fuera de su casa. Y, que dadas las características de corresponder a una guardería para hijos de funcionarios de una institución de salud, trabajo materno, sistema de previsión de salud, ingresos económicos promedio y número de hijos, pudiera acercarse al costo de infecciones respiratorias de un importante número de niños en estas condiciones que asisten a estos centros en la ciudad de Santiago.

La elección del segundo cuatrimestre del año, otoño-invierno, evidentemente influyó en el número de casos detectados a consecuencia de la epidemiología de infecciones respiratorias incidentes en la comunidad, coincidiendo, por ejemplo, el mayor número de casos reportados en julio con el máximo número de ingresos en el Servicio de Pediatría del hospital en este mes.

Ahora bien, llama la atención por lo elevado del valor, que $64,2 \%$ de los asistentes a esta guardería infantil desarrollaran al menos un episodio de infección respiratoria durante el período de seguimiento. Esta cifra pudiese haber sido mayor dado que no existe asistencia continua de los menores inscritos; algunas madres sólo llevan a sus hijos el día de turno laboral en el hospital y otras evitan enviarlos, particularmente a lactantes, durante los meses de junio y julio. Sin embargo, la asistencia a la guardería infantil podría ser sólo uno de los factores de riesgo asociado ya que no se investigó, por ejemplo, la epidemiología mórbida concomitante en los diferentes hogares y no se dispone de grupo control de niños de la edad y cuidados en su domicilio habitual.

En relación a los diagnósticos médicos (dato aportado por las madres), en los lactantes se observó un predominio de infecciones respiratorias bajas a diferencia del predominio de infecciones altas en los preescolares, diferencias estadísticamente significativas, situación concordante con la incidencia descrita especialmente de cuadros bronquiales obstructivos, de reconocida mayor incidencia en el período de lactan$\mathrm{te}^{4,5}$.
En la resolución de las consultas por la morbilidad en estudio, 44,1\% acudió a médicos del extra-sistema y sólo $30 \%$ asistió al médico institucional asignado, lo que pudiese explicarse en parte por episodios que demandaran consulta en horario de tardes, noches o fines de semana. Este fenómeno pudiese requerir de alguna estrategia a fin de aumentar la centralización de las consultas en un pediatra institucional para unificar criterios y pautas adecuadas de manejo de las distintas patologías registradas.

Mención aparte merece el elevado consumo de antimicrobianos detectado en el presente estudio, que alcanzó a 42,6\% de los eventos mórbidos, especialmente al considerar el conocido predominio de la etiología viral en este período y, en segundo lugar, por la escasa concordancia entre el diagnóstico referido a la madre y la posterior indicación de terapia antimicrobiana, indicándoselos por ejemplo, a aproximadamente un tercio de los pacientes con resfrío común, faringitis y bronquitis obstructiva y a la totalidad de los pacientes pre-escolares con herpangina. Este hecho pone en evidencia que nunca es suficiente la difusión de contenidos relacionados con el uso racional de antimicrobianos y son necesarias políticas educativas continuas al respecto.

Reconociendo que en el ámbito del impacto económico, sólo se midieron costos directos, merece ser destacado el elevado valor total alcanzado como promedio final por evento respiratorio, mayor en lactantes (\$ 68.577- US 129) como gasto compartido, pero que en lo particular, y considerando el nivel de ingresos de la población en seguimiento, el incurrir en estos gastos tiene repercusión en el presupuesto familiar representando cada evento infeccioso respiratorio con consulta médica en lactantes un desembolso de aproximadamente el $10 \%$ de su ingreso económico mensual.

Los ítems que marcan el mayor valor son los fármacos y los subsidios por ausentismo. El valor cancelado por los padres en fármacos se encuentra subestimado dado la adquisición de algunos de ellos en forma de muestras médicas desde el hospital, no así en el cálculo total, en cuyo caso se consideró valor real; no obstante, este gasto pudiese ser disminuido a futuro con una juiciosa indicación de los medicamentos de apoyo sintomático $\mathrm{y}$, como se demuestra en esta experiencia, con una sustancial mejoría en la indicación de antimicrobianos y no empleándolos ante cuadros de etiología viral o dudosa etiología bacteriana. $\mathrm{Y}$ respecto de los subsidios, se demuestra particularmente en lactantes, que estas infecciones significan un elevado costo institucional o estatal secundario al pago de licencias médicas por enfermedad de hijo bajo 1 año de edad o permisos administrativos, que además 
determinaron disminución en los días trabajados con pérdida de productividad laboral, efecto no cuantificado.

Existen pocas publicaciones referidas a costos por morbilidad respiratoria, pero comparativamente, existe un reporte estadounidense $\mathrm{e}^{12}$ de costo directo promedio efectuado en 1999 por episodio de infección respiratoria en preescolares con síndrome de Down (muestra con $86 \%$ de resfríos comunes) estimado en US 76, superando en $50 \%$ al costo obtenido en este estudio de \$28.913 equivalente aproximadamente a US 54 en el mismo grupo etario, pero evidentemente con realidades poco comparables.

Finalmente, reconociendo que en este ámbito las infecciones respiratorias son de difícil prevención ${ }^{13}$, la magnitud costo-efectiva de las intervenciones reportadas son poco concluyentes, ya sea por la metodología empleada o por los tópicos evaluados, y con la mayoría de los estudios dirigidos a infecciones gastrointestinales ${ }^{14}$. Sin embargo, parece razonable incorporar medidas como lavado de manos, programas de educación y especialmente supervisión, eventual exclusión del menor de la guardería infantil, prácticas como limpieza de juguetes y objetos tocados por los niños y la adhesión a programas de vacunación ${ }^{15}$, focalizando esfuerzos en los niños más pequeños y con factores de riesgo particulares.

En conclusión, dado el elevado consumo de antimicrobianos y considerando principalmente la información presentada referida a costos, estos datos debieran servir como un diagnóstico del impacto económico familiar y en un contexto de país que motiven la realización y supervisión de recomendaciones pre- ventivas por las autoridades de salud, con aportes de las sociedades científicas de Pediatría e Infectología.

\section{Resumen}

Se evaluó mediante estudio descriptivo, características y costos directos de infecciones respiratorias en 140 niños que asisten a sala cuna y jardín infantil. Se consignó diagnóstico, exámenes, fármacos, kinesioterapia, ausentismo, licencias médicas y hospitalización. Se analizan 202 eventos respiratorios en 90 niños: $75(37,1 \%)$ en 30 lactantes y $127(62,8 \%)$ en 60 preescolares. Hubo $61,3 \%$ de infecciones respiratorias bajas en lactantes versus 39,4\% en pre-escolares $(p<0,002)$. Existió indicación de antimicrobianos en $42,6 \%$ de las consultas. Se encontró mayor costo en lactantes respecto de consulta médica, kinesioterapia, exámenes de laboratorio y pago de licencias médicas o permisos $(\mathrm{p}<0,001)$. El costo promedio total de una infección respiratoria alcanzó a \$ 68.577 en lactantes y \$28.130 en pre-escolares $(p<0,001)$. Con predominio de infecciones bajas en lactantes, elevado consumo de antimicrobianos y alto impacto económico, esta realidad amerita focalizar programas de intervención.

\section{Agradecimientos}

Nuestros más sinceros agradecimientos al equipo de educadoras de párvulos y a las madres de los niños de sala cuna y jardín infantil, por permitirnos gentilmente realizar el presente estudio.

\section{Referencias}

1.- Churchil R, Pickering L. Infection control challenges in child-care center. Infect Dis Clin North Am 1997; 2: 347-63.

2.- Haskins R, Kotch J. Day care and illness: evidence, costs, and public policy. Pediatrics 1986; 77: S951-81.

3.- Robinson J. Enfermedades infecciosas en escuelas y jardines maternales. Pediatr Rev 2001; 22: 39-46.

4.- Van Woensel J, Van Aalderen W, Kimpen J. Viral lower respiratory tract infections in infants and young children. Br Med J 2003; 327:36-40.

5.- García M. Ordobás M, Calvo C, González M, Aguilar J, Arregui A, et al. Infecciones virales de vía respiratoria inferior en lactantes hospitalizados: etiología, características clínicas y factores de riesgo. An Esp Pediatr 2001; 55: 101-7.
6.- Goldmann D. Transmission of viral respiratory infection in the home. Pediatr Infect Dis J 2000; 19: 97-102.

7.- Musher D. How contagious are common respiratory tract infections. N Engl J Med 2003; 348: 1256-66.

8.- Trucco O, Prado V, Inostroza J, Cabrera E, Teran R, Bravo I, et al. Prevalencia de Streptococcus pneumoniae resistente a penicilina en niños que asisten a jardines infantiles en Santiago. Rev Chil Pediatr 1996; 67: 195-9.

9.- Nafstad P, Hagen J, Oie L, Magnus P, Jaakkola J. Day care centers and respiratory health. Pediatrics 1999; 103: 753-8.

10.- Simoes E. Environmental and demographic risk factors for respiratory syncytial virus lower respiratory tract disease. J Pediatrics 2003; 143: 118-26.

11.- Carabin H, Gyorkos T, Soto J, Penrod J, Lawrence J, Collet J P. Estimation of direct and indirect costs because of common infections in toddlers attending day care centres. Pediatrics 1999; 103: 556-64.

12.- Ackerman S, Duff S, Dennehy P, Mafilos M, Krilov L. Economic impact of an infection control education program in a specialized preschool setting. Pediatrics 2001; 108: 102-10.

13.- Kotch J, Weigle K, Weber D, Cliford R, Harms T, Loda F, et al. Evaluation of an hygienic intervention in child day care centers. Pediatrics 1994; 94: 991-4.

14.- Huskins W Ch. Transmission and control of infections in out-of-home child care. Pediatr Infect Dis J 2000; 19: S106-10.

15.- American Academy of Pediatrics. Children in out of home child care. In Pickering LK, ed. RedBook 2003: Report of the Committee on Infectious Diseases.26 edición Elk Grove Village IL: 123-37. 